\title{
Protease-Activatable Scaffold Proteins as Versatile Molecular Hubs in Synthetic Signaling Networks
}

\author{
Stijn J. A. Aper, ${ }^{\dagger}$ Anniek den Hamer, ${ }^{\dagger}$ Simone F. A. Wouters, Lenne J. M. Lemmens, \\ Christian Ottmann, ${ }^{\circledR}$ Luc Brunsveld, ${ }^{\circledR}$ and Maarten Merkx*(0)
}

Laboratory of Chemical Biology and Institute for Complex Molecular Systems (ICMS), Department of Biomedical Engineering, Eindhoven University of Technology, P.O. Box 513, 5600 MB Eindhoven, The Netherlands

Supporting Information

ABSTRACT: Protease signaling and scaffold-induced control of protein-protein interactions represent two important mechanisms for intracellular signaling. Here we report a generic and modular approach to control the activity of scaffolding proteins by protease activity, creating versatile molecular platforms to construct synthetic signaling networks. Using 143-3 proteins as a structurally well-characterized and important class of scaffold proteins, three different architectures were explored to achieve optimal protease-mediated control of scaffold activity, fusing either one or two monovalent inhibitory ExoS peptides or a single bivalent ExoS peptide to T14-3-3 using protease-cleavable linkers. Analysis of scaffolding activity

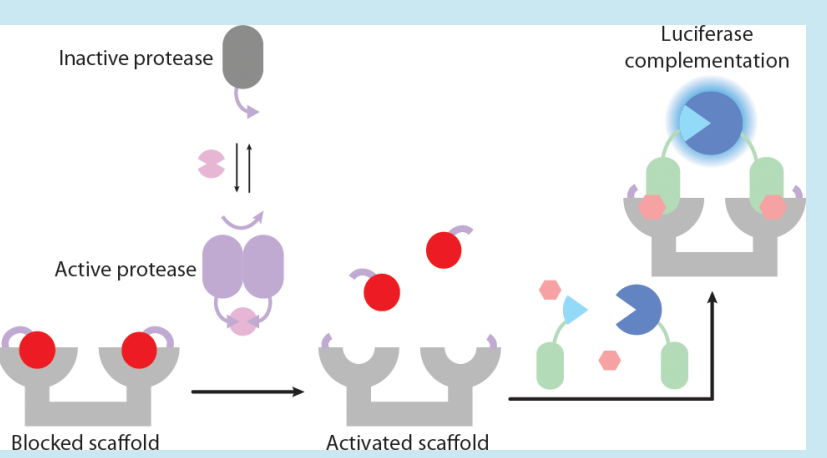
before and after protease-induced cleavage revealed optimal control of 14-3-3 activity for the system that contained monovalent ExoS peptides fused to both the $\mathrm{N}$-and C-terminus, each blocking a single T14-3-3 binding site. The protease-activatable 14-3-3 scaffolds were successfully applied to construct a three-step signaling cascade in which dimerization and activation of FGGcaspase-9 on an orthogonal supramolecular platform resulted in activation of a 14-3-3 scaffold, which in turn allowed 14-3-3templated complementation of a split-luciferase. In addition, by combining 14-3-3-templated activation of caspase-9 with a caspase-9-activatable 14-3-3 scaffold, the first example of a synthetic self-activating protease signaling network was created. Protease-activatable 14-3-3 proteins thus represent a modular platform whose properties can be rationally engineered to fit different applications, both to create artificial in vitro synthetic molecular networks and as a novel signaling hub to re-engineer intracellular signaling pathways.

KEYWORDS: 14-3-3 protein, protein engineering, proteases, signaling cascade, self-activation, synthetic biology

$\mathrm{C}$ ellular signaling networks are capable of highly sophisticated signal integration and processing, elegantly controlling a wide variety of cellular processes with high temporal and spatial control. This control is achieved using a number of fundamental information processing steps, including the use of enzyme-controlled reversible covalent modifications (phosporylation, acetylation, ubiquitination etc.), the compartmentalization of proteins in organelles, the recruitment of otherwise weakly associating proteins on membrane surfaces or dedicated scaffold proteins, and the use of protease-mediated activation of inactive preproteins or zymogens. $^{1-3}$ These signaling pathways need to operate simultaneously within the crowded environment of a cell, requiring a delicate balance between orthogonality and communication between different signal transduction pathways. The inherent modularity of natural signaling networks enables the application of synthetic biology strategies, both to rewire existing signaling pathways and to recreate essential features of biological signal processing using in vitro biomolecular networks. Thus far, most efforts in the latter area of bottom-up synthetic biology ${ }^{4}$ have focused on one specific type of signal transduction (protease, phosphorylation or scaffolding), but the construction of synthetic protein-based signaling networks that combine different signaling strategies is mostly lacking.

In this work we report a generic strategy to integrate two important signal transduction mechanisms, protease-mediated signaling and template-mediated assembly of protein complex formation. The classic example of protease signaling is the blood coagulation cascade, where sequential activation of serine proteases (coagulation factors) is essential for hemostasis. ${ }^{5,6}$ Since this finding, the importance of protease-based signal transduction has been established in numerous pathways including cell proliferation (ADAM10 and $\gamma$-secretase ${ }^{7}$ ), cell death $\left(\right.$ caspases $^{8}$ ) and the immune response (cathepsins ${ }^{9}$ ). Protease signaling often involves cascades of sequential activation of pro-enzymes, which provides multiple levels of control and an efficient mechanism of signal amplification. The inherent modularity of protease-based signaling and the

Received: $\quad$ May 21, 2018

Published: August 20, 2018 
possibility for signal amplification make protease activity an attractive tool to control and construct protein-based signaling networks, both in vivo and in vitro. For example, Lim and coworkers developed a synthetic Notch receptor that upon antigen binding to its artificial receptor domain gets cleaved, releasing a non-native transcriptional activator domain that induces the expression of a second chimeric antigen receptor. ${ }^{10}$ Huck and co-workers recently reported the in vitro construction of a trypsine-based reaction network that showed oscillations in enzyme activation by combining autoactivation of the protease trypsin with delayed feedback. ${ }^{11-13}$ Modular protein switches based on autoinhibited proteases have been engineered by Alexandrov and co-workers and used as biosensors to detect protease activity, ligand binding and protein-protein interactions. ${ }^{14,15}$

The recruitment of proteins on scaffold proteins represents another important mechanism for spatiotemporal control of signal transduction cascades. ${ }^{16}$ Scaffold proteins are highly flexible and modular platforms that enable the cell to perform a wide variety of functions using a limited number of components. $^{3,16-18}$ Well-known examples include Crk, ${ }^{19}$ a family of scaffold proteins involved in cellular transformation, cytoskeletal changes and phagocytosis, and the Ste5- and KSRscaffold proteins involved in the MAPK pathway. ${ }^{20-22}$ Another major class of natural scaffold proteins are the 14-3-3 proteins. 14-3-3 proteins exist as constitutive homo- or heterodimers based on 7 different isoforms $(\beta, \varepsilon, \eta, \gamma, \zeta, \sigma, \tau),{ }^{23-25}$ with each monomer containing an amphipathic ligand-binding groove that allows specific binding of target proteins that typically contain a phosphorylated serine and threonine binding motif. 14-3-3 proteins lack intrinsic enzymatic activity but exert their biological activity by enhancing the interaction of two target proteins, by binding a target protein to prevent its interactions with other biomolecules, or shield its sequence-specific or structural features for example to protect against degradation. ${ }^{25,26}$ Through these mechanisms $14-3-3$ is involved in the regulation of a wide variety of cellular processes including signal transduction, metabolism, cytoskeletal dynamics, cellcycle progression and apoptosis. ${ }^{23-25}$ An attractive feature of 14-3-3-mediated scaffolding is that the interaction of 14-3-3 with certain target proteins can be reversibly induced by addition of small molecules such as fusicoccin. This property has been used to develop a chemically induced dimerization system based on the fusicoccin-promoted interaction between the tobacco plant 14-3-3 protein (T14-3-3c) and a C-terminal peptide from the $\mathrm{H}^{+}$-ATPase PMA2 (CT52). ${ }^{27}$ More recently, we used this T14-3-3c-CT52 interaction to dimerize two monomers of apoptosis-initiating caspase- 9 that were fused to CT52, and thereby activated caspase- 9 in a fusicoccindependent manner on a T14-3-3c scaffold. ${ }^{28}$

While endogenous 14-3-3-mediated signal transduction is intimately connected with phosporylation-based signaling, we here introduce a generic approach to control 14-3-3 activity by proteases. Protease-based control of 14-3-3 activity is achieved by fusion of inhibitory ExoS peptides via protease-cleavable flexible peptide linkers. Three different architectures are explored to achieve optimal control of 14-3-3 scaffolding activity using either one or two monovalent ExoS peptides or a single bivalent ExoS peptide. The relative efficiency of these architectures to block the 14-3-3 templating activity is systematically studied using the previously reported fusicoccin-induced dimerization and activation of caspase-9. The protease activatable 14-3-3 scaffolds are successfully applied to construct synthetic biomolecular signaling networks, including a three-step (enzyme $\rightarrow$ scaffold $\rightarrow$ enzyme) synthetic signaling cascade and a self-activating protease signaling network.

\section{RESULTS AND DISCUSSION}

Design of Protease-Activatable 14-3-3 Proteins. In this study we used the tobacco 14-3-3 homodimer (T14-3$3 c \Delta C$, from here called $\mathrm{T} 14-3-3)$ to assess various control strategies. This plant 14-3-3 protein is attractive for the bottom-up construction of orthogonal signaling networks, because it is less likely to bind to endogeneous 14-3-3 target proteins in mammalian cells. ${ }^{27}$ Two tobacco 14-3-3 monomers were covalently connected using a flexible (Gly-Gly-Ser) ${ }_{10}{ }^{-}$ linker to allow specific intramolecular control of the scaffolding activity of a T14-3-3 dimer. 14-3-3 activity was blocked by intramolecular binding of one or two inhibitory ExoS peptides (Figure 1). The ExoS peptide originates from the C-terminal

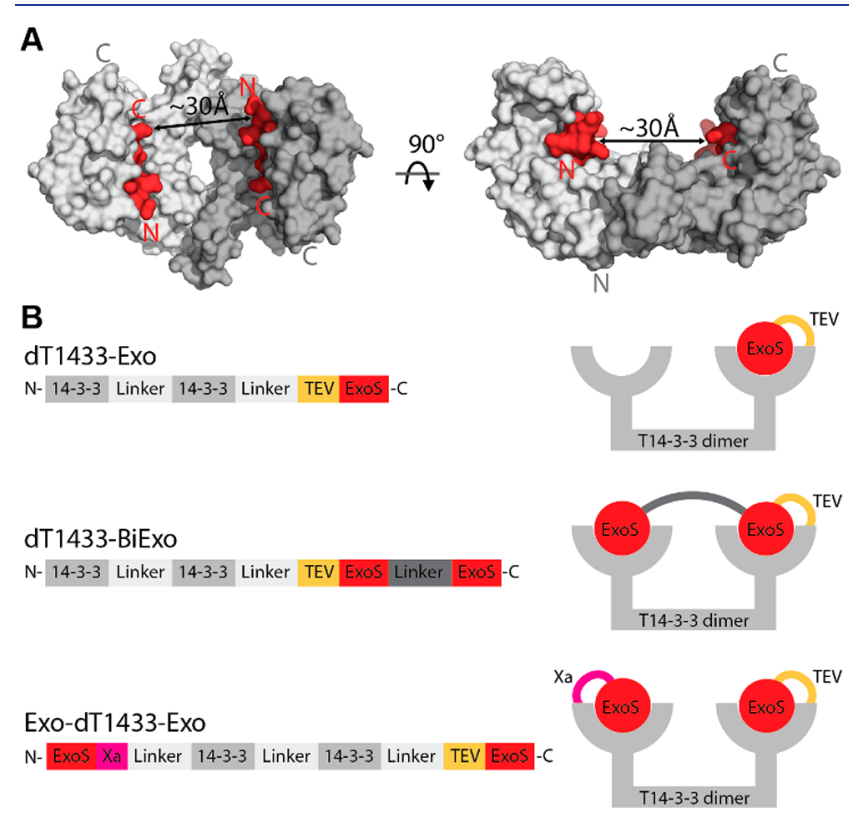

Figure 1. Engineered protease-activatable dT14-3-3 protein scaffolds. (A) Crystal structure of a 14-3-3 dimer (PDB: 4N7G) depicted in gray, each binding groove is occupied by an ExoS peptide depicted in red. (B) Schematic representation of domain structure and architecture of the three scaffolds used. Intramolecular binding of one monovalent ExoS peptide (top), one bivalent peptide (middle) or two monovalent ExoS peptides (bottom), to allow proteasecontrolled activation of the 14-3-3 scaffold. The 14-3-3 domains are fused to each other using a (Gly-Gly-Ser) $)_{10}$-linker, and the ExoS peptides (red) are connected to the 14-3-3 scaffold via (Gly-GlySer $)_{18}$-linkers. TEV protease and Factor Xa protease cleavage sites in those linkers are depicted in orange and magenta, respectively.

region of Pseudomonas aeruginosa toxin exoenzyme $S$ $\left({ }^{420}\right.$ QGLLDALDLAS $\left.{ }^{430}\right)$ and binds to $14-3-3$ proteins in a phosphorylation-independent manner. ${ }^{29}$ Three different designs for protease-activatable T14-3-3 were explored. In the first design one ExoS peptide is fused to the C-terminal T14-33 domain via a (Gly-Gly-Ser) 18 -linker that contains a TEV protease cleavage site, blocking a single T14-3-3 binding site (Figure 1; dT1433-Exo). The second design is similar, but contains a bivalent ExoS peptide that binds both T14-3-3 binding sites simultaneously (Figure 1; dT1433-BiExo). The 
A

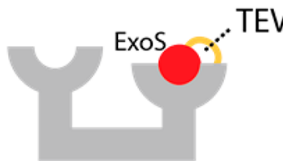

T14-3-3 dimer
TEV

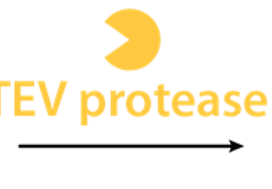

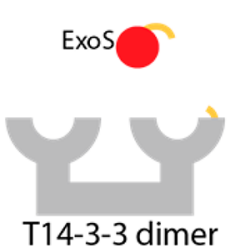

T14-3-3 dimer

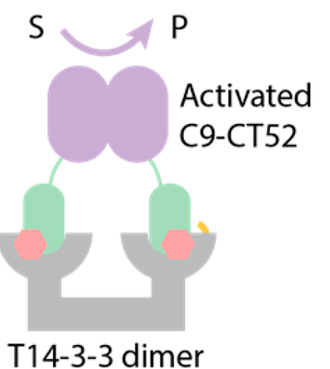

T14-3-3 dimer
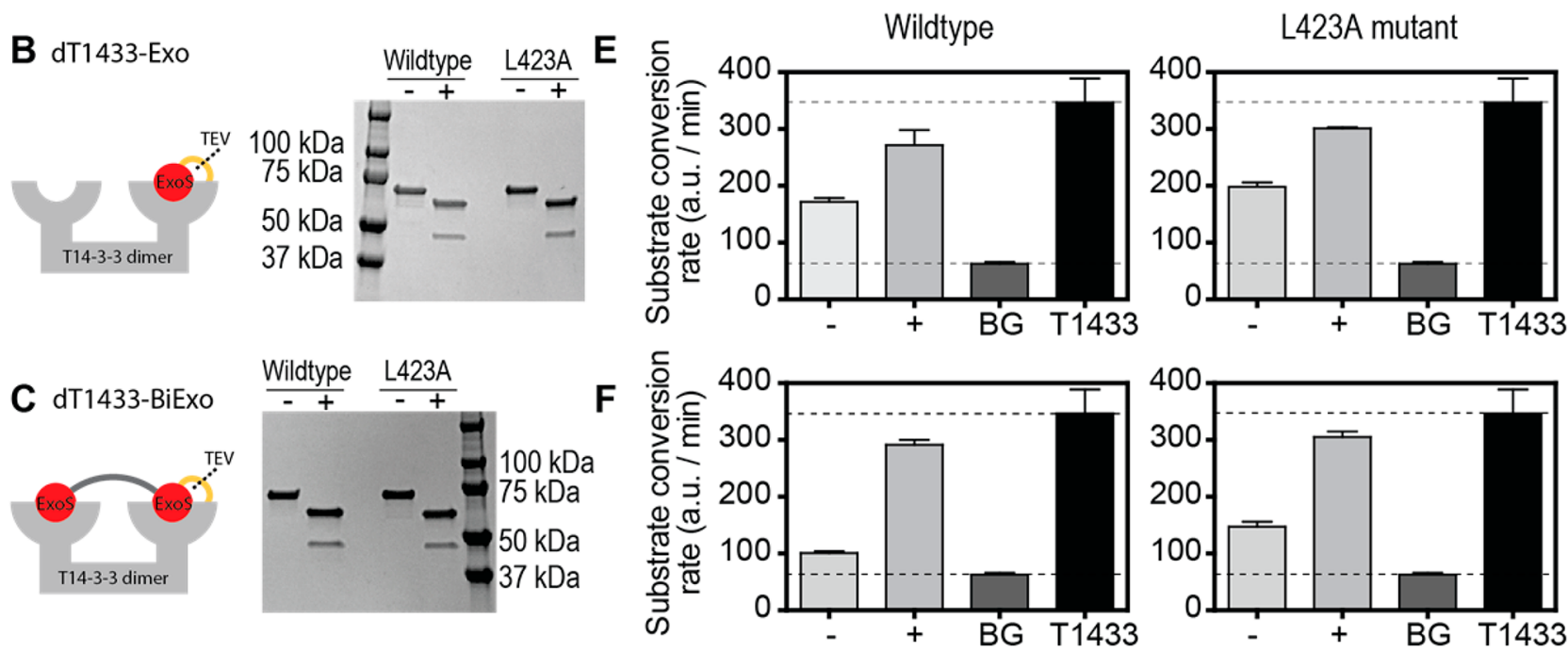

D Exo-dT1433-Exo

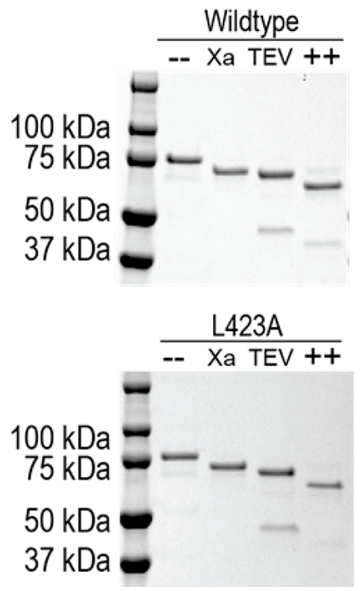

$\mathbf{G}$
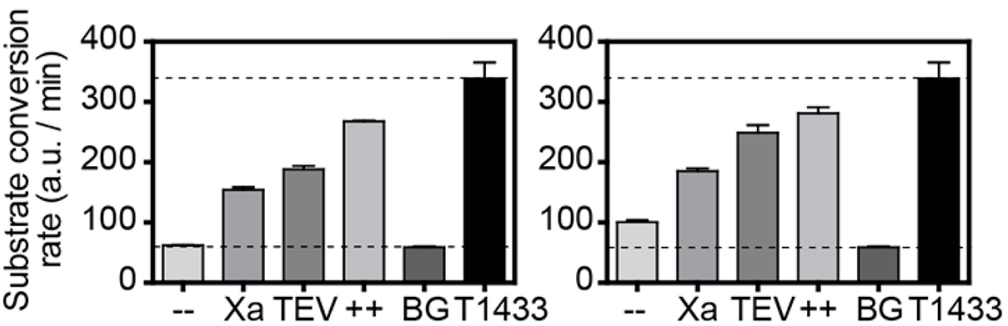

Figure 2. Protease-regulated dT14-3-3 scaffold activation. (A) Schematic representation of dT14-3-3 scaffold activation. After cleavage of the ExoS peptide by the protease (TEV and/or Xa), dT14-3-3 is mixed with the fusion protein caspase-9-CT52 (C9-CT52) and small-molecule fusicoccin (FC). Fusicoccin-induced binding of C9-CT52 to dT14-3-3 induces C9 dimerization and subsequent activation. (B-D) SDS-PAGE gel analysis showing cleavage of noncleaved $(-)$ or protease-cleaved $(+)$ dT14-3-3 constructs containing either wildtype or L423A mutant ExoS peptide(s) after $2 \mathrm{~h}$ of incubation at $25^{\circ} \mathrm{C}$ in $20 \mathrm{mM}$ Hepes ( $\left.\mathrm{pH} 8.0\right), 100 \mathrm{mM} \mathrm{NaCl}$ and $1 \mathrm{mM} \mathrm{CaCl}$. The band at $48 \mathrm{kDa}$ corresponds to the TEV protease. (E) C9-CT52 activation controlled by dT1433-Exo (left) and dT1433-Exo* (right). (F) C9-CT52 activation controlled by dT1433-BiExo (left) and dT1433-BiExo* (right). (G) C9-CT52 activation controlled by Exo-dT1433-Exo (left) and Exo*-dT1433-Exo* (right). BG represents the background activity displayed by C9-CT52 in the absence of 14-3-3-scaffold protein. Substrate conversion rates (a.u./min) were determined from the initial slopes of the fluorescence emission measured over time. Error bars represent $\mathrm{SD}(n=3)$.

two ExoS sequences in the bivalent ExoS are linked by a $(\mathrm{Gly})_{10}$-linker, as this linker length was found to be sufficient to cover the $30 \AA$ distance between the two $14-3-3 \zeta$ binding pockets for binding of a natural bivalent peptide derived from protein kinase $\mathrm{C}-\varepsilon .{ }^{30}$ In the third approach two monovalent ExoS peptides are attached to the T14-3-3 dimer via (Gly-GlySer) 18 -linkers, one to the $\mathrm{N}$-terminus and the other to the $\mathrm{C}$ terminus of the engineered T14-3-3 platform (Figure 1; ExodT1433-Exo). The N-terminal linker contains a Factor Xa protease cleavage site, and the C-terminal linker includes a TEV protease recognition site. This construct thus requires cleavage by two proteases to become fully liberated, which should allow dual input control of the T14-3-3 scaffold protein.

Binding of Mono- and Bivalent ExoS Peptides to T143-3. The affinity of the interaction between 14-3-3 and the monovalent and bivalent ExoS peptides is important for successful control of 14-3-3 scaffold activity. Fluorescence polarization titration experiments were used to systematically 
investigate the binding of fluorescently labeled monovalent and bivalent peptides containing either the wild-type ExoS peptide or the L423A, L426A, L428A, and L423A/L426A mutants (Figure S1, Table S1-S2). These mutations were chosen because hydrophobic interactions of these leucines dominate the interaction with the 14-3-3 binding site, and mutations of these residues have been shown to reduce 14-3-3-binding mediated cellular toxicity of the full exoenzyme S. ${ }^{31-34}$ Wildtype monovalent ExoS bound to T14-3-3 with a $K_{\mathrm{d}}$ of $14.1 \pm$ $0.9 \mu \mathrm{M}$, which is 10 -fold weaker than the $K_{\mathrm{d}}$ of $1.14 \pm 0.05 \mu \mathrm{M}$ reported previously for binding of wt ExoS to 14-3-3 $\zeta .^{31}$ T143-3 binding was essentially abolished for all monovalent mutant peptides except for the L423A mutant, which showed a $\sim 9$-fold decrease in affinity compared to the wild-type peptide $\left(K_{\mathrm{d}}=127 \pm 16 \mu \mathrm{M}\right)$. Titration of T14-3-3 to bivalent wt ExoS revealed a $K_{d}$ of $45.5 \pm 8.5 \mathrm{nM}$, which represents a 300 -fold increase in affinity between mono- and bivalent ExoS binding. A similar $\sim 100$-fold affinity enhancement has been observed for the 14-3-3 $\zeta$ binding of two monovalent phosphorylated peptides of protein kinase $\mathrm{C}-\varepsilon$ fused using the same (Gly) $10^{-}$ linker. ${ }^{33}$ The bivalent L423A mutant ExoS peptide also showed enhanced binding compared to monovalent L423A ExoS, although the increase in affinity was more modest, showing a 20 -fold lower $K_{\mathrm{d}}$ of $5.9 \pm 0.9 \mu \mathrm{M}$. The bivalent stabilization can be quantitatively understood using a thermodynamic model that describes the binding of the bivalent peptide to T14-3-3 $\left(K_{\mathrm{d}, \mathrm{bi}}\right)$, as a function of the monovalent binding affinity $\left(K_{\mathrm{d} \text {,mono }}\right)$ and the effective concentration $\left(C_{\text {eff }}\right)$ for binding the second T14-3-3 binding site after the first has been bound (Figure S2). The model yields an effective concentration of $\sim 1 \mathrm{mM}$ and explains how the enhancement in affinity for bivalent ligands depends on the affinity of the monovalent peptide.

Protease-Triggered Activation of ExoS-Inhibited T143-3 Scaffolds. The mono- and bivalent ExoS and ExoS L423A peptides together provide a set of inhibitors with affinities ranging between $45 \mathrm{nM}$ to $127 \mu \mathrm{M}$, allowing a systematic screening of the optimal affinity for protease-activatable 14-3-3 constructs. For all three designs shown in Figure 1, proteaseactivatable T14-3-3 scaffold proteins with either wild-type peptide (Exo) or the L423A mutant (Exo*) were made, yielding a total of 6 different constructs: dT1433-Exo, dT1433Exo*, dT1433-BiExo, dT1433-BiExo*, Exo-dT1433-Exo, Exo*-dT1433-Exo*. The scaffold proteins were expressed in E. coli BL21(DE3) and sequentially purified by $\mathrm{Ni}^{2+}$ and StrepTactin affinity chromatography using their N-terminal His-tag and C-terminal Strep-tag, respectively.

All proteins were obtained in high purity and sufficient yield $(\geq 1 \mathrm{mg} / \mathrm{L})$ for our studies (Figure S3). Please note that this yield could probably be further improved by a systematic screening for optimal expression conditions (temperature, medium, fermentation) and a more efficient purification procedure. SDS-PAGE analysis showed that each of the scaffold proteins was efficiently and specifically cleaved by its target protease into the expected molecular fragments (Figure 2B,C,D, Figure S4).

To monitor 14-3-3 scaffold activity, we employed the fusicoccin-stabilized interaction between 14-3-3 and a caspase9-CT52-fusion protein. ${ }^{28}$ Binding of this fusion protein on the 14-3-3 scaffold promotes caspase-9 (C9) dimerization, resulting in caspase- 9 activation that can be monitored by cleavage of a fluorogenic substrate (Figure 2A). Because CT52 has been shown to bind to the T14-3-3 dimer with a $K_{d}$ of $\sim 1$
$\mathrm{nM}$ in the presence of fusicoccin, ${ }^{35}$ this assay provides a rigorous test for the ability of the ExoS peptide to block the 143-3 site. For each scaffold protein, 14-3-3-templated caspase-9 activity was determined before and after protease-cleavage and compared to a control in which the same concentration of native T14-3-3 dimer was used (representing 100\% activity) and a control in which no $14-3-3$ was present (representing $0 \%$ activity).

Scaffold proteins containing a single ExoS peptide at the Cterminus of the 14-3-3 dimer (dT1433-Exo and dT1433-Exo*) showed scaffold activities of $40 \%$ and $50 \%$, respectively (Figure $2 \mathrm{E}$ ). In both cases, 14-3-3 scaffold activity was almost completely restored following protease-cleavage. As expected, more efficient inhibition of 14-3-3 activity was observed for the variant with wt ExoS. Although the affinity of the wild-type ExoS peptide $\left(K_{\mathrm{d}}=14.1 \pm 0.9 \mu \mathrm{M}\right)$ is high enough to ensure essentially complete intramolecular complex formation, the scaffold activity is only partially inhibited because C9-CT52 strongly competes with this interaction in the presence of FC. The bivalent ExoS peptides proved more effective in blocking the 14-3-3-templated caspase-9 activation than the monovalent ExoS peptide, showing a residual activity of $\sim 15 \%$ for the construct with wt ExoS peptides (dT1433-BiExo, Figure 2F, left) and $30 \%$ for the construct with the bivalent L423A mutant ExoS (Figure 2F, right). Despite the strong bivalent interaction between the 14-3-3 dimer and the bivalent ExoS peptide, protease cleavage still resulted in efficient activation of the 14-3-3 scaffold, yielding restored activity levels between 80 and $85 \%$ (Figure $2 \mathrm{~F}$ ).

The most effective control of T14-3-3 scaffolding activity was observed for the constructs having monomeric ExoS peptides fused to each end of the 14-3-3 dimer. The construct with two wt ExoS peptides (Exo-dT1433-Exo) showed complete inhibition of scaffold-activity, while the scaffold protein with ExoS-L423A displayed $\sim 15 \%$ remaining activity (Figure $2 \mathrm{G}$ ). Despite this strong blockage, efficient restoration of scaffold activity was observed in both cases upon treatment with both proteases leading to 75 and $80 \%$ recovery, respectively. As a result, the Exo-dT1433-Exo displayed the largest dynamic range of scaffold activation of all six proteaseactivatable T14-3-3 scaffold variants. While both proteases are required to achieve maximal activation, each of the proteases by itself also induced partial restoration of scaffold activity. Digestion of the proteins with Factor Xa protease resulted in scaffold activities of $\sim 35 \%$ and $\sim 45 \%$ for the constructs containing wild-type and mutant ExoS peptides (Figure 2G), respectively, corresponding well to the data obtained for dT1433-Exo and dT1433-Exo*. Remarkably, the TEV protease-cleaved proteins displayed a significantly higher C9 activity than the Factor Xa-digested proteins, with scaffold activity levels of $\sim 45 \%$ and $\sim 70 \%$ for the resulting ExodT1433 and Exo*-dT1433. Possibly the attachment of the linker connecting the ExoS peptide to the $\mathrm{N}$-terminus of the $\mathrm{N}$-terminal T14-3-3 monomer, which is oriented away from the T14-3-3 binding grooves, led to a lower effective concentration of the peptide close to its binding pocket(s). This effect might have been enhanced by the reversed orientation of the ExoS peptide in the T14-3-3 binding groove compared to other target peptides, which substantially increases the distance between the C-terminus of the ExoS peptide and the N-terminus of the N-terminal T14-3-3 monomer (PDB: 2O02). ${ }^{32}$ Further, the presence of a His-tag 
A

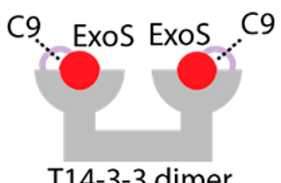

T14-3-3 dimer

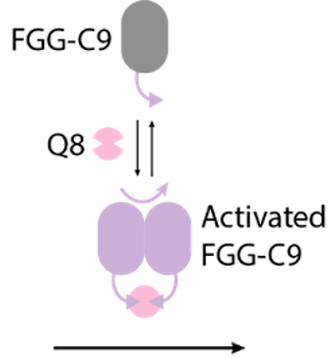

dT1433-LEHD-BiExo*

B

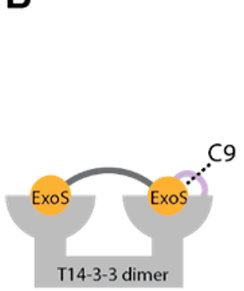

dT1433-LEHD-BiExo*
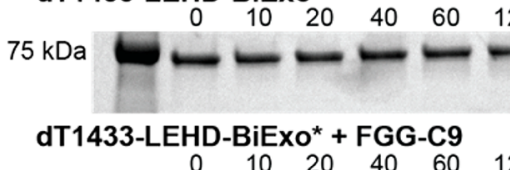

$75 \mathrm{kDa}$

$\begin{array}{llllll}0 & 10 & 20 & 40 & 60 & 120 \text { minutes }\end{array}$

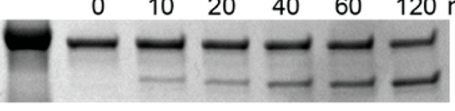

dT1433-LEHD-BiExo* + FGG-C9 + Q8

$75 \mathrm{kDa}$ $\begin{array}{llllll}0 & 10 & 20 & 40 & 60 & 120 \text { minutes }\end{array}$

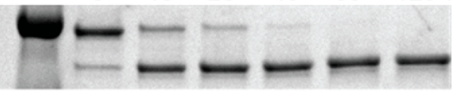

D Exo-LEHD-dT1433-LEHD-Exo
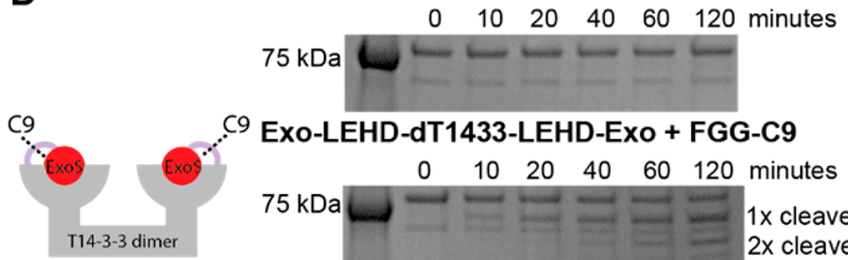

Exo-LEHD-dT1433 -LEHD-EXo

Exo-LEHD-dT1433-LEHD-Exo + FGG-C9
$\begin{array}{lllllll}0 & 10 & 20 & 40 & 60 & 120 \text { minutes }\end{array}$

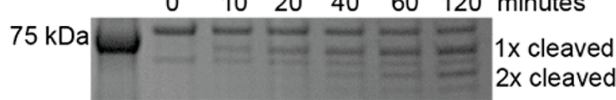

Exo-LEHD-dT1433-LEHD-Exo + FGG-C9 + Q8

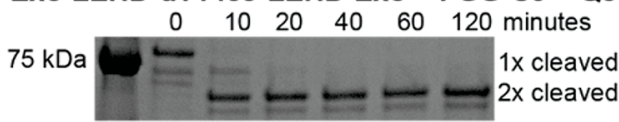

$\mathbf{F}$

dT1433-LEHD-BiExo*

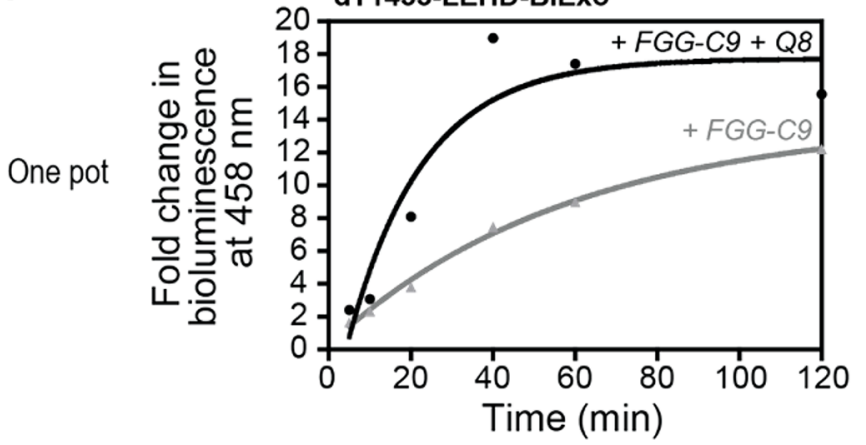

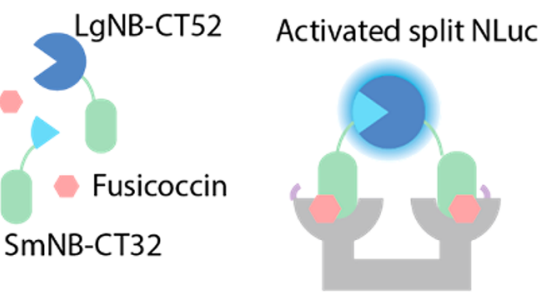

C

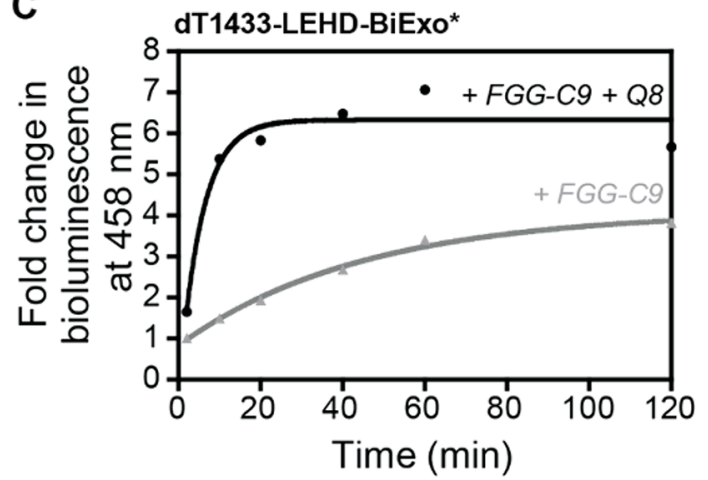

E

Exo-LEHD-dT1433-LEHD-Exo

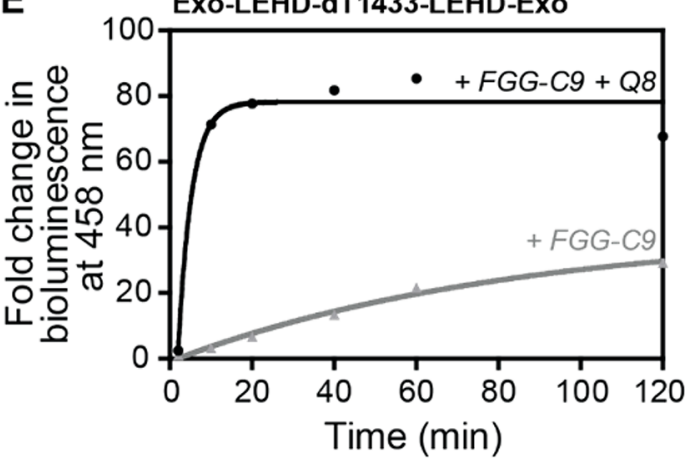

G

Exo-LEHD-dT1433-LEHD-Exo

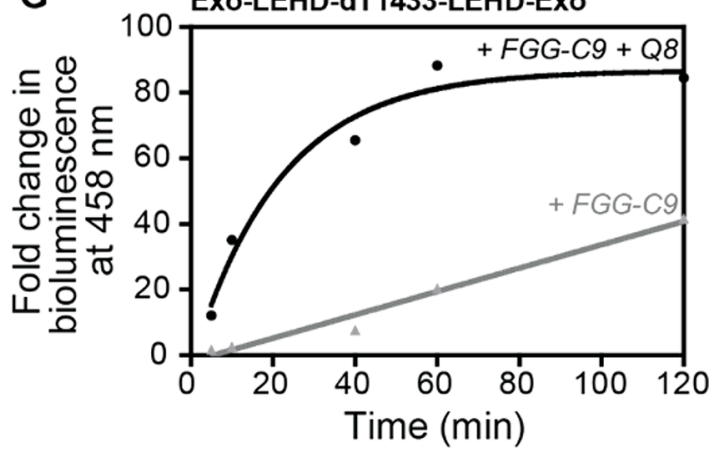

Figure 3. Synthetic signaling cascade based on caspase-9 activatable dT14-3-3. (A) Schematic representation of signaling cascade in which caspase9 containing an N-terminal FGG-motif (FGG-C9) can be activated by cucurbit[8] uril(Q8)-mediated dimerization in a supramolecular fashion. The active caspase-9 cleaves off the ExoS peptides from the Exo-LEHD-dT1433-LEHD-Exo scaffold, which induces NanoBiT luciferase complementation by allowing fusicoccin-enhanced LgNB-CT52 and SmNB-CT32 binding. (B,D) SDS-PAGE gel analysis of the cleavage of dT1433-LEHD-BiExo* (B) or Exo-LEHD-dT1433-LEHD-Exo (D) by FGG-C9 over time, in the presence and absence of Q8. (C,E) Bioluminescent readout of the synthetic signaling cascade containing the dT1433-LEHD-BiExo* scaffold (C) or the Exo-LEHD-dT1433-LEHDExo scaffold (E), in the presence (black) and absence of Q8 (gray). Two $\mu \mathrm{M}$ scaffold was incubated with $5 \mu \mathrm{M}$ FGG-C9, and $10 \mu \mathrm{M} \mathrm{Q8}$ at $37{ }^{\circ} \mathrm{C}$. At different time points these samples were diluted 5 times, and mixed with $40 \mathrm{nM} \mathrm{LgNB}-\mathrm{CT} 52,40 \mathrm{nM}$ SmNB-CT32, $5 \mu \mathrm{M} \mathrm{FC,} 1 \mathrm{mg} / \mathrm{mL}$ BSA, and 2000 -fold diluted furimazine, in $20 \mathrm{mM} \mathrm{NaH}_{2} \mathrm{PO}_{4}(\mathrm{pH} 7.0), 150 \mathrm{mM} \mathrm{NaCl}, 1 \mathrm{mM}$ EDTA, and $2 \mathrm{mM}$ TCEP. The fold change in bioluminescence at $458 \mathrm{~nm}$ was determined from the bioluminescence emission spectrum measured at each time point compared with the bioluminescent emission spectra obtained for the scaffold that had not been incubated with FGG-C9 and Q8. (F,G) Synthetic signaling cascade performed in a one-pot assay. Fold change in bioluminescence emission at $458 \mathrm{~nm}$ over time observed for $400 \mathrm{nM}$ dT1433-LEHD-BiExo* (F) or Exo-LEHD-dT1433-LEHD-Exo (G) that was mixed with $5 \mu \mathrm{M}$ FGG-C9, in the presence and absence of $10 \mu \mathrm{M}$ Q8, and further incubated with 40 nM LgNB-CT52, $40 \mathrm{nM}$ SmNB-CT32, $5 \mu \mathrm{M}$ FC, $1 \mathrm{mg} / \mathrm{mL}$ BSA, in $20 \mathrm{mM} \mathrm{NaH}_{2} \mathrm{PO}_{4}$ (pH 7.0), $150 \mathrm{mM} \mathrm{NaCl}, 1 \mathrm{mM}$ EDTA, and $2 \mathrm{mM}$ TCEP, at $37{ }^{\circ} \mathrm{C}$. At different time points furimazine (final dilution $2000 \times$ ) was added. 
A

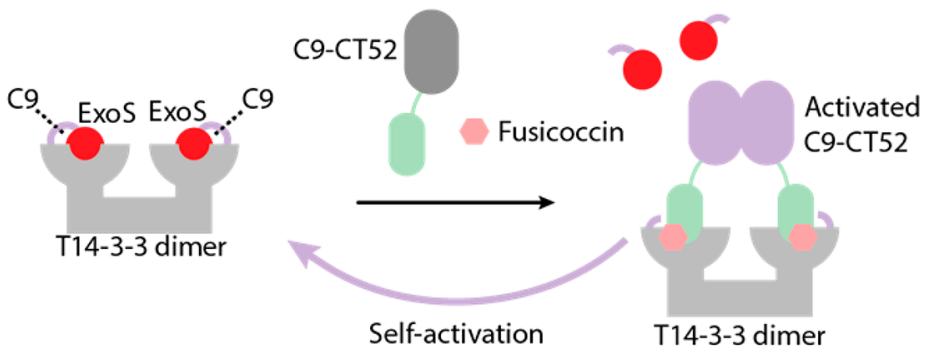

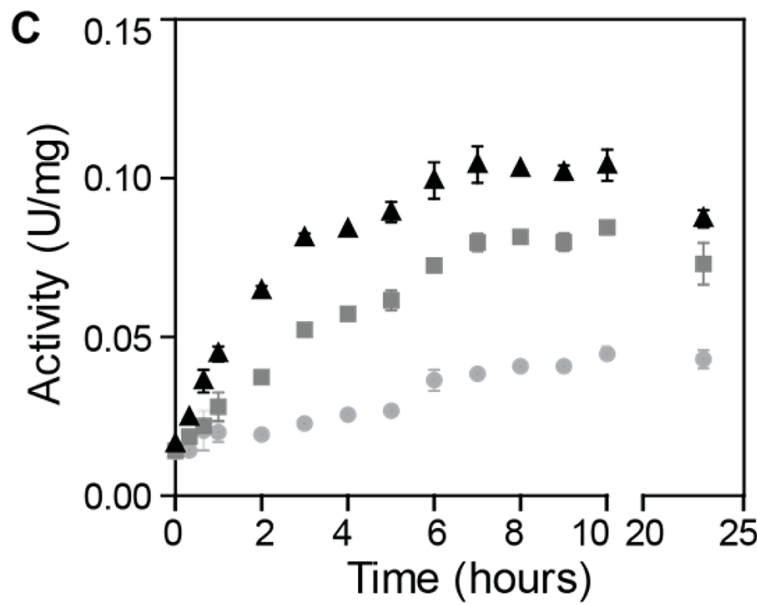

B

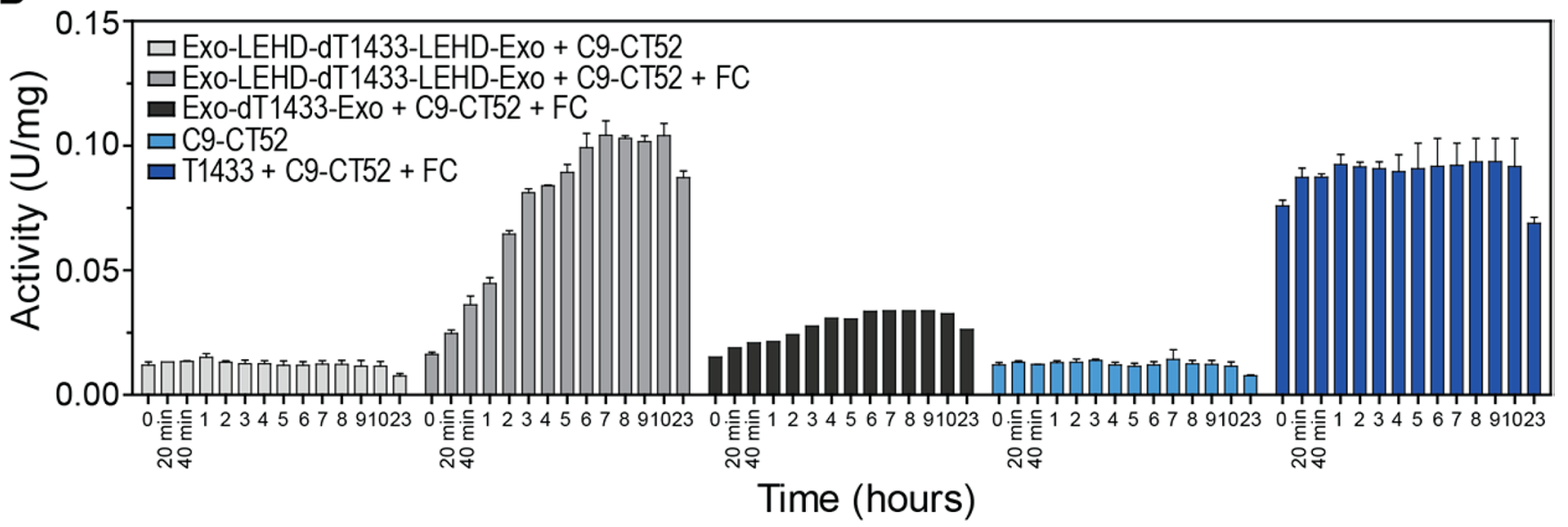

Figure 4. Self-activation assay using the Exo-LEHD-dT1433-LEHD-Exo scaffold. (A) Schematic representation of self-activation of the Exo-LEHDdT1433-LEHD-Exo scaffold in the presence of C9-CT52 and FC. Background activation leads to cleavage of the scaffold which induces dimerization and activation of C9-CT52 on the scaffold, enhancing the cleavage of the scaffold, resulting in higher C9-CT52 activation. (B) Activation $\left(\mathrm{U} \mathrm{mg}^{-1}\right)$ of C9-CT52 $(200 \mathrm{nM})$ on the Exo-LEHD-dT1433-LEHD-Exo scaffold $(400 \mathrm{nM})$ probed by a fluorogenic substrate (AcLEHD-AFC) in the absence (light gray) and presence of $10 \mu \mathrm{M} \mathrm{FC} \mathrm{(dark} \mathrm{gray).} \mathrm{Controls} \mathrm{are} \mathrm{shown} \mathrm{as} \mathrm{well} \mathrm{of} \mathrm{the} \mathrm{C9-CT52} \mathrm{activity} \mathrm{on} \mathrm{the} \mathrm{Exo-}$ dT1433-Exo scaffold (400 nM) in the presence of $100 \mathrm{nM} \mathrm{C9-CT52} \mathrm{and} 10 \mu \mathrm{M}$ FC (black) and the background activity of solely C9-CT52 (100 $\mathrm{nM}$, light blue). Maximum activity that can be reached is obtained by measuring the activation of C9-CT52 (100 nM) in the presence of the native dT14-3-3 scaffold ( $400 \mathrm{nM}$ ) and $10 \mu \mathrm{M}$ FC (dark blue). Samples were incubated at $18{ }^{\circ} \mathrm{C}$ in $20 \mathrm{mM} \mathrm{NaH}_{2} \mathrm{PO}_{4}(\mathrm{pH} 7.0), 150 \mathrm{mM} \mathrm{NaCl}, 1 \mathrm{mM}$ EDTA, and $2 \mathrm{mM}$ TCEP. At each time point Ac-LEHD-AFC was added to a final concentration of $200 \mu \mathrm{M}$. Error bars represent SEM $(n=2)$. (C) Activation $\left(\mathrm{U} \mathrm{mg}^{-1}\right)$ of C9-CT52 on the Exo-LEHD-dT1433-LEHD-Exo scaffold from the same assay as in B and Figure S9 (200 nM C9-CT52 black triangle, $100 \mathrm{nM}$ C9-CT52 gray square, $50 \mathrm{nM} \mathrm{C9-CT52} \mathrm{light} \mathrm{gray} \mathrm{circle),} \mathrm{error} \mathrm{bars} \mathrm{represent} \mathrm{SEM}(n=2)$.

and thrombin cleavage site directly upstream of the N-terminal ExoS peptide may have reduced its binding affinity.

Synthetic Signaling Cascade. As a next step we combined the protease-controlled 14-3-3 platform with previously developed molecular signaling modules to yield synthetic signaling cascades. We previously reported a supramolecular system to control caspase-9 dimerization based on the cucurbit[8] uril (Q8) mediated dimerization of FGG-modified proteins. ${ }^{36}$ In this system addition of the macrocyclic host Q8 can be used to control the dimerizaton of caspase-9 with an N-terminally fused FGG motif (FGG-C9) (Figure 3). ${ }^{36}$ To allow coupling of this Q8-induced dimerization system upstream of the protease-activable 14-33 scaffolds, we introduced caspase- 9 recognition sites in two protease-activatable 14-3-3 scaffold proteins, dT1433-BiExo* (dT1433-LEHD-BiExo*, Figure 3B) and Exo-dT1433-Exo (Exo-LEHD-dT1433-LEHD-Exo, Figure 3D). These scaffolds were chosen as they were blocked with different stringency, while the residual affinities of the ExoS and bivalent ExoS* peptides formed upon protease-cleavage for 14-3-3 are similar.
Since caspase- 9 activitity is used as an input, an alternative output platform to measure 14-3-3 scaffold activity was required. We therefore developed a new read-out system for 14-3-3-templated protein dimerization based on complementation of the NanoBiT split-luciferase system (Figure S5A, Figure $3 \mathrm{~A}) .{ }^{37}$ The large NanoBiT fragment ( $\mathrm{LgNB}$ ) was fused to a CT52 peptide (LgNB-CT52), and the small NanoBiT fragment was fused to CT32 (SmNB-CT32), an N-terminally truncated version of CT52 which has similar FC-controllable T14-3-3 binding properties. To ensure low background activity in the absence of a template, a low affinity variant of small NanoBit was used $\left(K_{\mathrm{d}}=190 \mu \mathrm{M}\right)$. The split NanoLuc system provided a very robust read-out of 14-3-3-templating activity, showing a $\sim 100$-fold increase in bioluminescence emission upon addition of T14-3-3 in the presence of FC (Figure S5B). The higher response observed for the split Nanoluc system compared to the C9-CT52 system can be attributed to the lower amount of complementation in the absence of the 14-3-3 scaffold. 
Having established orthogonal input and output functions for the 14-3-3 scaffold, we assessed its performance in a threestep signaling cascade whereby Q8-induced FGG-C9 activation leads to activation of the dT14-3-3 scaffold, which subsequently allows scaffolding of both LgNB-CT52 and SmNB-CT32, resulting in complementation and restoration of NanoBiT luciferase activity (Figure 3A). dT1433-LEHDBiExo* and Exo-LEHD-dT1433-LEHD-Exo were incubated with FGG-C9 in the absence and presence of Q8 and samples were taken at various time points for analysis by SDS-PAGE and bioluminescent actvity assays. SDS-PAGE analysis showed almost complete removal of the ExoS peptides for both scaffolds within $20 \mathrm{~min}$ in the presence of Q8, while only $\sim 50 \%$ cleavage was observed after $2 \mathrm{~h}$ in the absence of Q8. The corresponding activation of 14-3-3 templating activity was monitored by measuring the bioluminescence intensity after addition of LgNB-CT52, SmNB-CT32, FC and furimazine to each sample (Figure S6). In the presence of Q8, a strong increase in bioluminescence was observed within 10-20 min, which coincides with the kinetics of protease-induced scaffold cleavage observed with SDS-PAGE analysis. (Figure 3B,C,D,E, Figure S6, S7, S8). In the absence of Q8, self-complemented FGG-C9 also induced an increase in bioluminescent emission, but this activation was much slower than in the presence of Q8. The fully cleaved dT1433-LEHD-BiExo* and Exo-LEHDdT1433-LEHD-Exo scaffolds showed a $\sim 6$-fold and $\sim 80$-fold increase of the NanoBiT bioluminescence compared to the nonactivated scaffolds, respectively (Figure 3C,E). The higher level of activation for Exo-LEHD-dT1433-LEHD-Exo compared to that of dT1433-LEHD-BiExo* is consistent with the more stringent inhibition of the undigested scaffold, which was also observed for the C9-CT52 activation (Figure 2F,G).

To assess whether the different reactions in the signaling cascade are orthogonal we also monitored the increase of Q8triggered 14-3-3-templated NanoLuc complementation by incubation of all components in one pot. Similar levels of luciferase activity enhancement were reached upon addition of Q8, showing a $\sim 17$ - and $\sim 86$-fold increase in split-NanoBiT activation for the dT1433-LEHD-BiExo* and Exo-LEHDdT1433-LEHD-Exo scaffold, respectively (Figure 3F,G). While the reaction rates in the absence of $\mathrm{Q} 8$ were not influenced, the Q8-induced cleavage appeared somewhat slower compared to the separately incubated reactions. Nonetheless, these results confirm that the reaction components are mutually compatible and operate essentially orthogonal to each other.

Self-Activation. An intruiging property of protease-based signaling is the possibility for self-activation. Self-activation is a powerful mechanism of positive feedback control that has been reported for a variety of proteases including caspases, ${ }^{38-40}$ the retroviral proteases involved in $\mathrm{HIV}^{41}$ and trypsinogen. ${ }^{42,43}$ The successful construction of caspase-9 activated 14-3-3 scaffolds provides an attractive synthetic platform to study selfactivation of protease activity. By replacing the Q8-activatable caspase-9 with the original caspase-9-CT52, a system can be created in which C9-CT52 functions as both in- and output of the protease-controlled 14-3-3 scaffold (Figure 4). Selfactivation was evaluated using the Exo-LEHD-dT1433LEHD-Exo scaffold, as this scaffold showed the strongest inhibition and therefore the highest fold increase in activation. Self-activation of the scaffold was assessed over time by measuring C9-CT52 activity using the fluorogenic substrate Ac-LEHD-AFC, in the absence and presence of FC (Figure 4). To investigate the influence of the C9-CT52 concentration on the activation kinetics, experiments were done using 50, 100, or $200 \mathrm{nM}$ C9-CT52 and $400 \mathrm{nM}$ of Exo-LEHD-dT1433LEHD-Exo scaffold. As a reference, the background activity of C9-CT52 alone was measured, and the maximum activity that could be reached was measured by the activation of C9-CT52 on the regular 14-3-3 scaffold in the presence of FC. In the absence of FC, C9-CT52 activity on the caspase-9 activatable scaffold was similar to the background activity observed in the absence of any scaffold protein (Figure 4B, Figure S9) over a period of $23 \mathrm{~h}$. In the presence of FC, the activity of C9-CT52 on the scaffold slowly increased over time, reaching maximal activity after $6-7 \mathrm{~h}$ for the two highest concentrations of C9CT52 (100, $200 \mathrm{nM})$, while $\sim 50 \%$ reactivation was obtained after $23 \mathrm{~h}$ when using $50 \mathrm{nM}$ C9-CT52. Importantly, selfactivation of caspase- 9 activity was not observed when the ExodT1433-Exo scaffold was used, as this scaffold cannot be cleaved by caspase- 9 . The slightly higher caspase- 9 activity that is observed in the presence of Exo-dT1433-Exo compared to the background, can be attributed to competition between C9CT52 and the ExoS peptides for binding to the scaffold in the presence of FC. For all samples a small decrease in C9-CT52 activity was observed after $23 \mathrm{~h}$, which probably reflects a decrease in intrinsic enzyme stability. The initial velocity of caspase- 9 activation roughly correlates with the concentration of C9-CT52, showing a 1.8-fold increase between $50 \mathrm{nM}$ and $100 \mathrm{nM}$, and 3.7-fold increase between $50 \mathrm{nM}$ and $200 \mathrm{nM}$, respectively (Figure 4B,C, Figure S9). The slow 14-3-3 activation kinetics are probably due to a combination a high $K_{\mathrm{M}}$ and a low $k_{\text {cat }}$ of caspase 9 for the 14-3-3-scaffold proteins. These parameters are likely to be similar to those for the AcLEDH-AFC peptide probe, for which a $K_{\mathrm{M}}$ of $600 \mu \mathrm{M}$ and $k_{\text {cat }}$ of $0.2 \mathrm{~s}^{-1}$ have been determined, which corresponds to a $k_{\text {cat }} /$ $K_{\mathrm{M}}=0.33 \times 10^{-3} \mu \mathrm{M}^{-1} \mathrm{~s}^{-1}$ or $1.2 \mu \mathrm{M}^{-1} \mathrm{~h}^{-1} \cdot{ }^{28,44-46}$ As far as we know, this system represents the first successful example of an in vitro protease signaling network with positive feedback loop.

\section{- CONCLUSION AND OUTLOOK}

In this work we introduced a generic and modular approach to enable protease-based control over protein scaffolding, one of the key mechanisms used in signal transduction in nature. Inspired by the mechanism used in many natural zymogens, different protein architectures were explored in which the 14-33 binding sites were intramolecularly blocked by one or more ExoS peptides. The modularity of the system enabled easy exchange of protease recognition sites and allowed systematic tuning of the switching properties by tuning the affinity and interaction of the ExoS peptide and 14-3-3. The ability to rationally modulate the relative strength of the intramolecular blocking allows adjustment of the platform depending on the strength of the downstream protein-protein interaction; e.g., in this work we used the strong interaction between 14-3-3 and CT52 in the presence of fusicoccin, which required strong intramolecular blocking of both 14-3-3 binding sites using wt ExoS. However, when using 14-3-3 target proteins with lower affinities (e.g., phosphorylated peptides or proteins), weaker intramolecular blocking architectures may be more suitable.

The protease-activatable 14-3-3 scaffold proteins developed here represent versatile molecular hubs to integrate proteaseand scaffold-based signal transduction in in vitro protein-based molecular logic networks. ${ }^{15,47}$ The modularity of the platform provides ample opportunity to program various form of logic operations, a first example of which was provided by Exo- 
dT14-3-3-Exo whose full activation required the presence of two different proteases. Similarly, OR gates could be obtained by incorporating multiple protease recognition sites in a single linker, while more robust AND-gates could be created by fusing two wild-type bivalent ExoS peptides to the T14-3-3 dimer. Next to altering the protease-controlled 14-3-3 scaffold itself, the scaffold could be combined with other proteasebased synthetic signaling networks, such as the proteaseactivatable switches developed by Stein and Alexandrov, ${ }^{14,15}$ which could be introduced both upstream or downstream of the protease-controlled 14-3-3 scaffold.

The protease-activable 14-3-3 platform presented here therefore provides an orthogonal and tractable molecular model system to understand the molecular mechanism of scaffold activity regulation. Compared to natural proteases, where self-activation typically results from autocatalytic cleavage of a precursor pro-enzyme, our system provides enhanced control of self-activation, both by adjusting the concentration of the C9-CT52 and by regulating the concentration of the small-molecule inducer fusicoccin. This approach could be easily extended to other proteases that require dimerization for activation such as the HIV-1 protease $^{48,49}$ and provide more insight into the critical aspects of controlling protease-based signaling, imbalances of which have been implicated in in several diseases such as cancer, osteoporosis, neurological disorders and cardiovascular and inflammatory diseases. ${ }^{50}$ The genetic encoding of proteaseactivatable 14-3-3 should also allow in situ applications, either as part of synthetic, orthogonal signaling networks or by integration with endogeneous protease-signaling networks involved in cell proliferation, cell cycle control, apoptosis and the immune reponse. In addition, protease-activatable 14-3-3 activity could be connected to some of the protease-inducible or -inducing systems that have been engineered in recent years, including split-caspases, ${ }^{51}$ split-TEVs, ${ }^{52-54}$ chimeric adapters that reroute tyrosine kinase signaling, ${ }^{55}$ membrane-bound receptors for monitoring of protein-protein interactions (PPIs) ${ }^{56}$ or photoactivatable proteases. ${ }^{57}$ Finally, the orthogonal control over the activity of specific 14-3-3 homo- or heterodimers $^{24}$ offered by protease-activatable 14-3-3 may provide an attractive approach to further unravel the signaling roles of 14-3-3 proteins in living cells.

\section{MATERIALS AND METHODS}

Protease Cleavage and Caspase-9 Activation. Optimal cleavage conditions were determined by incubating ExodT1433-Exo protein $(2 \mu \mathrm{M}$ in $80 \mu \mathrm{L})$ with 3 different concentrations of Factor Xa protease (Novagen, 0.1, 0.2, and $0.5 \mu \mathrm{g}$ ) and TEV protease (Promega, 0.5, 1.0, and 2.5 U) for different times $(10,30,75$, and $120 \mathrm{~min})$ and monitoring cleavage efficiency on a 4-20\% Mini-PROTEAN TGX Precast SDS-PAGE gel (Bio-Rad). Having established the optimal cleavage conditions, $2 \mu \mathrm{M}$ of each of the proteins that only had a TEV cleavage site was digested using $4 \mathrm{U}$ TEV protease for 2 $\mathrm{h}$ at $25^{\circ} \mathrm{C}$, in $80 \mu \mathrm{L}$ of $20 \mathrm{mM}$ HEPES ( $\mathrm{pH} \mathrm{8.0),} 100 \mathrm{mM}$ $\mathrm{NaCl}$ and $1 \mathrm{mM} \mathrm{CaCl}$. The proteins that also contained a Factor Xa cleavage site were first incubated with $0.8 \mu \mathrm{g}$ Factor $\mathrm{Xa}$ protease in the aforementioned buffer for $2 \mathrm{~h}$ at $25{ }^{\circ} \mathrm{C}$, followed by the TEV protease cleavage step. Subsequently, 2 mM EDTA was added to the cleavage mixtures.

Caspase- 9 activation assays were performed by mixing 400 $\mathrm{nM}$ 14-3-3 protein ( $5 \times$ diluted from the $2 \mu \mathrm{M}$ protease incubation/control mixtures) with $100 \mathrm{nM}$ C9-CT52, $5 \mu \mathrm{M}$
FC in $100 \mu \mathrm{L}$ of $20 \mathrm{mM} \mathrm{NaH}_{2} \mathrm{PO}_{4}$ (pH 7.0), $150 \mathrm{mM} \mathrm{NaCl}, 1$ mM EDTA, $1 \mathrm{mM}$ TCEP, $1 \mathrm{mM}$ DTT, and $1 \mathrm{mg} / \mathrm{mL} \mathrm{BSA}$, at $37{ }^{\circ} \mathrm{C}$. The mixtures were prepared in a black, flat-bottom 96 well plate (Greiner Bio-One). After $\sim 20 \mathrm{~min}$ incubation, 200 $\mu \mathrm{M}$ Ac-LEHD-AFC substrate (Enzo Life Sciences) was added, and the fluorescence emission measurement was started on a Tecan Safire2 microplate reader for $90 \mathrm{~min}$ with $1 \mathrm{~min}$ intervals. Fluorescence emission was measured at $505 \mathrm{~nm}(5$ $\mathrm{nm}$ bandwidth) using excitation at $400 \mathrm{~nm}$ ( $5 \mathrm{~nm}$ bandwidth).

Synthetic Signaling Cascade. In the two-step assay, first $2 \mu \mathrm{M}$ dT1433-LEHD-BiExo* or Exo-LEHD-dT1433-LEHDExo scaffold was incubated with $5 \mu \mathrm{M}$ FGG-C9 and $10 \mu \mathrm{M}$ Q8 at $37^{\circ} \mathrm{C}$. Control mixtures without FGG-C9 and/or Q8 were prepared as well. Subsequently, at different time points these samples were diluted 5 times, and mixed with $40 \mathrm{nM}$ LgNBCT52, $40 \mathrm{nM}$ SmNB-CT32, $5 \mu \mathrm{M}$ FC, $1 \mathrm{mg} / \mathrm{mL}$ BSA, and 2000 -fold diluted furimazine, in $20 \mathrm{mM} \mathrm{NaH} \mathrm{PO}_{4}(\mathrm{pH} 7.0)$, $150 \mathrm{mM} \mathrm{NaCl}, 1 \mathrm{mM}$ EDTA, and $2 \mathrm{mM}$ TCEP. Bioluminescence emission was measured at 11 emission wavelengths equally distributed from 398 to $548 \mathrm{~nm}(20 \mathrm{~nm}$ bandwidth) on a Tecan Spark $10 \mathrm{M}$ plate reader using integration times of $100 \mathrm{~ms}$. Scaffold cleavage was simultaneously analyzed by SDS-PAGE gel analysis.

In the one-pot assays, $400 \mathrm{nM}$ dT1433-LEHD-BiExo* or Exo-LEHD-dT1433-LEHD-Exo was mixed with $5 \mu \mathrm{M}$ FGGC9 and $10 \mu \mathrm{M} \mathrm{Q8}$, in the presence of $40 \mathrm{nM}$ LgNB-CT52, 40 $\mathrm{nM}$ SmNB-CT32, $5 \mu \mathrm{M}$ FC, $1 \mathrm{mg} / \mathrm{mL}$ BSA, in $20 \mathrm{mM}$ $\mathrm{NaH}_{2} \mathrm{PO}_{4}$ (pH 7.0), $150 \mathrm{mM} \mathrm{NaCl}, 1 \mathrm{mM}$ EDTA, and $2 \mathrm{mM}$ TCEP, at $37{ }^{\circ} \mathrm{C}$. Control mixtures without FGG-C9 and/or Q8 were prepared as well. At different time points, furimazine (2000-fold diluted in final sample) was added, and bioluminescence emission was measured at $465 \pm 20 \mathrm{~nm}$ on a Tecan Spark $10 \mathrm{M}$ plate reader using an integration time of $100 \mathrm{~ms}$.

The bioluminescence emission increases over time were fitted using eq 1 assuming first order reaction kinetics. In eq 1 , $B_{0}$ is the bioluminescence emission at $t=0, B_{\mathrm{f}}$ the final bioluminescent emission when a plateau has been reached and $k$ is the rate constant.

$$
B=B_{0}+\left(B_{\mathrm{f}}-B_{0}\right)\left(1-\mathrm{e}^{-k t}\right)
$$

Self-Activation Assay. Exo-LEHD-dT1433-LEHD-Exo scaffold, Exo-dT1433-Exo or dT1433 (400 nM) was incubated with C9-CT52 (50, 100, or $200 \mathrm{nM})$ in the absence or presence of $10 \mu \mathrm{M} \mathrm{FC}$ at $18{ }^{\circ} \mathrm{C}$ in $20 \mathrm{mM} \mathrm{NaH}_{2} \mathrm{PO}_{4}(\mathrm{pH} 7.0)$, $150 \mathrm{mM} \mathrm{NaCl}, 1 \mathrm{mM}$ EDTA, and $2 \mathrm{mM}$ TCEP. A control mixture without scaffold and FC was prepared as well. Successively, at different time points fluorogenic substrate Ac-LEHD-AFC (final concentration $200 \mu \mathrm{M}$ ) was added and fluorescence intensity was measured on a Tecan Infinite F500 plate reader using an exication wavelength of $400 \mathrm{~nm}$ (bandwidth $20 \mathrm{~nm}$ ) and emission wavelength of $520 \mathrm{~nm}$ (bandwidth $25 \mathrm{~nm}$ ), a gain of 23 and integration time of $40 \mu \mathrm{s}$. Activity $\left(\mathrm{U} \mathrm{mg}^{-1}\right)$ was determined from the fluorescent traces and calculated as described before. ${ }^{28}$

\section{ASSOCIATED CONTENT}

\section{Supporting Information}

The Supporting Information is available free of charge on the ACS Publications website at DOI: 10.1021/acssynbio. 8 b00217. 
Cloning, expression, purification and SDS-PAGE analysis of scaffold proteins and split NanoLuc-CT52/CT32 proteins, peptide synthesis and purification, fluorescence polarization assays for ExoS peptide binding, thermodynamic model for bivalent binding to 14-3-3 scaffoldproteins, characterization of bioluminescent read-out system for caspase-9 activatable 14-3-3, SDS-PAGE and bioluminescent analysis of FGG-C9-mediated cleavage experiments, self-activation of Exo_LEHD-dT1433LEHD-Exo scaffold at different concentrations, nucleotide and amino acid sequences of various protein constructs (PDF)

\section{AUTHOR INFORMATION}

\section{Corresponding Author}

*Tel.: +31 40247 4728. E-mail: m.merkx@tue.nl.

\section{ORCID $\odot$}

Christian Ottmann: 0000-0001-7315-0315

Luc Brunsveld: 0000-0001-5675-511X

Maarten Merkx: 0000-0001-9484-3882

Author Contributions

${ }^{\dagger} \mathrm{SJAA}$ and $\mathrm{AdH}$ contributed equally.

Notes

The authors declare no competing financial interest.

\section{ACKNOWLEDGMENTS}

The authors thank Ir. Bas Rosier for providing the pET28aSUMO-FGG-C9 plasmid. The 2016 TU Eindhoven iGEM team (Stijn R. J. Hofstraat, Vera J. C. H. Koomen, Carolien E. de Korte, Marijn Kruit, Nynke M. de Leeuw, Laura Rijns, Tom J. van Sonsbeek, Bram M. van der Velden, and René Verhoef) is acknowledged for initial cloning, expression and purification of the protease-activatable 14-3-3 scaffold proteins, and for providing the pET28a-LgNB-CT52 plasmid. This work was supported by an ERC starting grant (ERC-2011-StG 280255) and by The Netherlands Organization for Scientific Research (NWO) via ECHO grant 700.59.013, Gravity Program 024.001.035 and VICI grant 016.150.366.

\section{REFERENCES}

(1) Lee, M. J., and Yaffe, M. B. (2016) Cold Spring Harbor Perspect. Biol. 8, 1.

(2) Turk, B., Turk, D., and Turk, V. (2012) EMBO J. 31 (7), 1630.

(3) Bhattacharyya, R. P., Reményi, A., Yeh, B. J., and Lim, W. A. (2006) Annu. Rev. Biochem. 75, 655.

(4) Lim, W. a. (2010) Nat. Rev. Mol. Cell Biol. 11 (6), 393.

(5) Davie, E. W., and Rattnoff, O. D. (1964) Science 145 (3638), 1310.

(6) Macfarlane, R. G. (1964) Nature 202, 498.

(7) Bray, S. (2006) Nat. Rev. Mol. Cell Biol. 7 (9), 678.

(8) Mcilwain, D. R., Berger, T., and Mak, T. W. (2013) Cold Spring Harbor Perspect. Biol. 5, a008656.

(9) Villadangos, J. A., Bryant, R. A. R., Deussing, J., Driessen, C., Lennon-Duménil, A.-M., Riese, R. J., Roth, W., Saftig, P., Shi, G.-P., Chapman, H. A., Peters, C., and Ploegh, H. L. (1999) Immunol. Rev. $172(1), 109$.

(10) Morsut, L., Roybal, K. T., Xiong, X., Gordley, R. M., Coyle, S. M., Thomson, M., and Lim, W. A. (2016) Cell 164 (4), 780.

(11) Semenov, S. N., Wong, A. S. Y., van der Made, R. M., Postma, S. G. J., Groen, J., van Roekel, H. W. H., de Greef, T. F. A., and Huck, W. T. S. (2015) Nat. Chem. 7 (2), 160.

(12) Postma, S. G. J., Vialshin, I. N., Gerritsen, C. Y., Bao, M., and Huck, W. T. S. (2017) Angew. Chem., Int. Ed. 56 (7), 1794.
(13) Wong, A. S. Y., Pogodaev, A. A., Vialshin, I. N., Helwig, B., and Huck, W. T. S. (2017) J. Am. Chem. Soc. 139, 8146.

(14) Stein, V., and Alexandrov, K. (2014) Proc. Natl. Acad. Sci. U. S. A. 111 (45), 15934.

(15) Stein, V., Nabi, M., and Alexandrov, K. (2017) ACS Synth. Biol. 6, 1337.

(16) Good, M. C., Zalatan, J. G., and Lim, W. A. (2011) Science 332 (6030), 680.

(17) Pan, C. Q., Sudol, M., Sheetz, M., and Low, B. C. (2012) Cell. Signalling 24 (11), 2143.

(18) Gordley, R. M., Bugaj, L. J., and Lim, W. A. (2016) Curr. Opin. Struct. Biol. 39, 106.

(19) Birge, R. B., Kalodimos, C., Inagaki, F., and Tanaka, S. (2009) Cell Commun. Signaling 7, 13.

(20) Good, M., Tang, G., Singleton, J., Reményi, A., and Lim, W. A. (2009) Cell 136 (6), 1085.

(21) Zalatan, J. G., Coyle, S. M., Rajan, S., Sidhu, S. S., and Lim, W. A. (2012) Science 337 (6099), 1218.

(22) Witzel, F., Maddison, L., and Blüthgen, N. (2012) Front. Physiol. 3, 1.

(23) Gardino, A. K., Smerdon, S. J., and Yaffe, M. B. (2006) Semin. Cancer Biol. 16 (3), 173.

(24) Yang, X., Lee, W. H., Sobott, F., Papagrigoriou, E., Robinson, C. V., Grossmann, J. G., Sundström, M., Doyle, D. A., and Elkins, J. M. (2006) Proc. Natl. Acad. Sci. U. S. A. 103 (46), 17237.

(25) Obsil, T., and Obsilova, V. (2011) Semin. Cell Dev. Biol. 22 (7), 663.

(26) Yaffe, M. B. (2002) FEBS Lett. 513 (1), 53.

(27) Skwarczynska, M., Molzan, M., and Ottmann, C. (2013) Proc. Natl. Acad. Sci. U. S. A. 110 (5), E377.

(28) den Hamer, A., Lemmens, L. J. M., Nijenhuis, M. A. D., Ottmann, C., Merkx, M., de Greef, T. F. A., and Brunsveld, L. (2017) ChemBioChem 18 (3), 331.

(29) Masters, S. C., Pederson, K. J., Zhang, L., Barbieri, J. T., and Fu, H. (1999) Biochemistry 38 (16), 5216.

(30) Kostelecky, B., Saurin, A. T., Purkiss, A., Parker, P. J., and McDonald, N. Q. (2009) EMBO Rep. 10 (9), 983.

(31) Glas, A., Bier, D., Hahne, G., Rademacher, C., Ottmann, C., and Grossmann, T. N. (2014) Angew. Chem., Int. Ed. 53 (9), 2489.

(32) Ottmann, C., Yasmin, L., Weyand, M., Veesenmeyer, J. L., Diaz, M. H., Palmer, R. H., Francis, M. S., Hauser, A. R., Wittinghofer, A., and Hallberg, B. (2007) EMBO J. 26 (3), 902.

(33) Yasmin, L., Jansson, A. L., Panahandeh, T., Palmer, R. H., Francis, M. S., and Hallberg, B. (2006) FEBS J. 273 (3), 638.

(34) Yasmin, L., Veesenmeyer, J. L., Diaz, M. H., Francis, M. S., Ottmann, C., Palmer, R. H., Hauser, A. R., and Hallberg, B. (2010) Biochem. J. 427, 217.

(35) Ottmann, C., Marco, S., Jaspert, N., Marcon, C., Schauer, N., Weyand, M., Vandermeeren, C., Duby, G., Boutry, M., Wittinghofer, A., Rigaud, J.-L., and Oecking, C. (2007) Mol. Cell 25 (3), 427.

(36) Dang, D. T., Nguyen, H. D., Merkx, M., and Brunsveld, L. (2013) Angew. Chem., Int. Ed. 52 (10), 2915.

(37) Dixon, A. S., Schwinn, M. K., Hall, M. P., Zimmerman, K., Otto, P., Lubben, T. H., Butler, B. L., Binkowski, B. F., MacHleidt, T., Kirkland, T. A., Wood, M. G., Eggers, C. T., Encell, L. P., and Wood, K. V. (2016) ACS Chem. Biol. 11 (2), 400.

(38) Tawa, P., Hell, K., Giroux, A., Grimm, E., Han, Y., Nicholson, D. W., and Xanthoudakis, S. (2004) Cell Death Differ. 11 (4), 439.

(39) Nuñez, G., Benedict, M. a, Hu, Y., and Inohara, N. (1998) Oncogene 17 (25), 3237.

(40) Klaiman, G., Champagne, N., and LeBlanc, A. C. (2009) Biochim. Biophys. Acta, Mol. Cell Res. 1793 (3), 592.

(41) Rose, J. R., Salto, R., and Craik, C. S. (1993) Mol. Biol. 101 (16), 11939.

(42) Davie, E. W., and Neurath, H. (1955) J. Biol. Chem. 212, 515.

(43) Kay, J., and Kassell, B. (1971) J. Biol. Chem. 246 (21), 6661.

(44) Yin, Q., Park, H. H., Chung, J. Y., Lin, S. C., Lo, Y. C., da Graca, L. S., Jiang, X., and Wu, H. (2006) Mol. Cell 22 (2), 259. 
(45) Pop, C., Timmer, J., Sperandio, S., and Salvesen, G. S. (2006) Mol. Cell 22 (2), 269.

(46) Garcia-Calvo, M., Peterson, E. P., Rasper, D. M., Vaillancourt, J. P., Zamboni, R., Nicholson, D. W., and Thornberry, N. A. (1999) Cell Death Differ. 6 (4), 362.

(47) Stein, V., and Alexandrov, K. (2015) Trends Biotechnol. 33 (2), 101.

(48) Ingr, M., Uhlikova, T., Strisovsky, K., Majerova, E., and Konvalinka, J. (2003) Protein Sci. 12 (10), 2173.

(49) Shekhawat, S. S., and Ghosh, I. (2011) Curr. Opin. Chem. Biol. 15 (6), 789.

(50) Turk, B. (2006) Nat. Rev. Drug Discovery 5 (9), 785.

(51) Wong, S., Mosabbir, A. A., and Truong, K. (2015) PLoS One 10 (8), 1.

(52) Wehr, M. C., Laage, R., Bolz, U., Fischer, T. M., Grünewald, S., Scheek, S., Bach, A., Nave, K.-A., and Rossner, M. J. (2006) Nat. Methods 3 (12), 985.

(53) Gray, D. C., Mahrus, S., and Wells, J. A. (2010) Cell 142 (4), 637.

(54) Djannatian, M. S., Galinski, S., Fischer, T. M., and Rossner, M. J. (2011) Anal. Biochem. 412 (2), 141.

(55) Howard, P. L., Chia, M. C., Del Rizzo, S., Liu, F.-F., and Pawson, T. (2003) Proc. Natl. Acad. Sci. U. S. A. 100 (20), 11267.

(56) Barnea, G., Strapps, W., Herrada, G., Berman, Y., Ong, J., Kloss, B., Axel, R., and Lee, K. (2008) Proc. Natl. Acad. Sci. U. S. A. 105 (1), 64.

(57) Zhou, X. X., Chung, H. K., Lam, A. J., and Lin, M. Z. (2012) Science 338 (6108), 810. 